Engineering Sustainability

Volume 000 Issue ESO00

Considerate constructors scheme: Glenfarg

Water Treatment Works

Murray, Forbes and Mason
Proceedings of the Institution of Civil Engineers Engineering Sustainability 000 Month 2010 Issue ES000 Pages 1-9 doi:

\title{
Considerate constructors scheme: [2] Glenfarg Water Treatment Works
}

1 Mike Murray BSC (Hons), MSc, PhD, MCIOB Lecturer in Construction Management (and part time CCS monitor) Department of Civil Engineering, University of Strathclyde, Glasgow, Scotland
2 Doug Forbes MEng (Hons), $\mathrm{PhD}$ Demonstration Projects Coordinator, Scottish Construction Centre University of Dundee, Dundee, Scotland

3 Steve Mason BEng (Hons), Civil Eng Project Manager, Black \& Veatch Ltd., Falkirk, Scotland
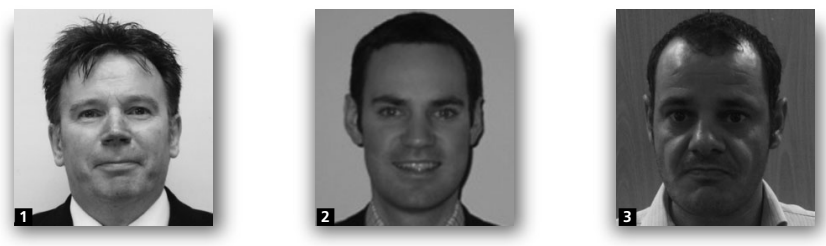

The project to modify Glenfarg Water Treatment Works by Scottish Water, working in conjunction with its partners Black and Veatch Ltd. and Scottish Water Solutions, received a gold award and 'the ultimate accolade' of 'The Most Considerate Site 2009' at the considerate constructors scheme (CCS) awards. Although previous projects undertaken by Scottish Water have achieved high considerate constructor scores, Glenfarg exceeded previous projects' standards. This level of performance was delivered across the eight categories of the scheme: considerate, environment, cleanliness, good neighbour, respectful, safe responsible and accountable. The steps the project team took under each of these categories to deliver the project are reviewed in this article. The article also outlines some of the challenges the project team faced while delivering such a high level of performance. Furthermore, the article makes particular reference to 'soft' management skills and the development of a project organisational culture that emphasised pride and passion through engagement of the workforce. Overall, the article presents valuable insights into how performing beyond the CCS requirements remains a dynamic and ongoing activity for all parties involved with the scheme.

\section{Introduction}

The need to improve the image of the UK construction industry has been a recurrent theme for discussion over the past two decades. The 'Building Britain 2001' report (Centre for Strategic Studies in Construction, 1988) identified the problem with the industry's reputation as being a self-inflicted wound that had arisen from a failure in public relations and a failure in the relationship of the industry with its clients. The media were seen to focus on failures in building projects rather than promote the positive. While this problem continues and was noted in subsequent reports (Bennett et al., 1989; National Contractors Group, 1991) a significant response with recommendations was not acted upon until Sir Michael Latham's (1994) 'Constructing the team' report reiterated the need for change. The report concluded that the industry should implement the recommendations made in the National Contractors Group report, namely, that the City of Westminster's considerate contractors scheme, established in 1987, should be immediately extended across the UK and should be fully implemented within 24 months. A subsequent report (The Construction Industry Board, 1996) expressed the need for a new model that would build upon the success of Westminster's scheme and promote the construction industry as caring and responsible. It was thought that through peer pressure and competition, a considerate constructors scheme (CCS) would improve actual levels of management, safety and quality, through participants' adherence to a code of good practice.

It is important to note that the considerate contractor scheme continues to be administered by the City of London (2010) and that participating contractors voluntarily abide by a five-point code of 'good' practice. Registration with this scheme is restricted to contractors working with London boroughs. The CCS (2010) differs from these council-administered schemes. Established in 1997 by representatives from the demand and supply sides, CCS has an eight-point code of 'considerate' practice and, unlike the council schemes, requires participating constructors to pay an administration fee. 
Engineering Sustainability

Volume 000 Issue ES000
Considerate constructors

scheme: Glenfarg Water

Treatment Works

Murray, Forbes and Mason

\section{The Considerate Constructors Scheme}

The scheme is concerned about any area of construction activity that may have a direct or indirect impact on the image of the industry as a whole. The main areas of concern are the environment, the workforce and the general public. The scheme operates voluntary site and company codes of considerate practice, to which participating construction companies and sites sign up. The scheme is a non-profitmaking independent organisation and is neither grant maintained nor funded by the government, and is solely financed by its registrations. The 40 000th site registered in December 2009. The scheme highlights issues associated with:

- improving a site's relationship with its neighbours

- improving the image of the site

- improving the processes and performance of the site

- improving the working conditions for site operatives

- advising and assisting in complaint resolution

- promoting best practice on sites

- encouraging environmental awareness.

Individual sites are registered, either by post or online, paying a registration fee that is determined by the project's value. Once registered, the site will receive scheme posters and other information to be properly and prominently displayed. All registered sites must then endeavour to comply with, or perform beyond the requirements of, the scheme's eight-point code of considerate practice. The monitor's role involves checking that sites comply with the code and putting forward recommendations that can help improve the site while complimenting sites when they are doing an excellent job. In addition, monitors look for the best sites to put forward for the national awards and collect statistical information (e.g. reportable accidents).

Although some site managers (Glass and Simmonds, 2007) have suggested that it is 'too easy to achieve the minimum standards', set out in the scheme's code, improving performance remains a dynamic and ongoing activity for all contractors involved with the scheme. As such, the scheme is always looking for the contractor, client and professionals to be inventive and imaginative in addition to being a proactive, accountable good neighbour and employer. These issues fall under the growing body of knowledge related to corporate social responsibility (Barthorpe, 2010; Jones and Comfort, 2006; Loosemore and Phua, 2011; Murray and Dainty, 2009) and it is noticeable that contractors (e.g. Gleeson, 2005) who participate in the scheme typically feature their CCS achievements within their corporate social responsibility reports.

\subsection{Considerate constructors scheme annual awards: most considerate site}

The CCS annual national site awards are given to the highest scoring $\left(71 \frac{1}{2} \%\right)$ of sites, which have completed in the previous year. The awards recognise sites' excellent standards of consideration towards their workforce, their neighbours and the environment. Any registered site is eligible to win a national award, providing that the site, or registered phase of it, has completed. An independent panel reviews all eligible sites and decides whether a site has reached the standard required to win and what level (gold, silver, and bronze) of award it should receive. The selection is based on the points given by the scheme's monitor, as verified against the national marking averages. The monitor uses a checklist to assess the relevant issues that are pertinent to a site, and each of the eight sections is given a score in which $1 / 5$ would indicate a severe breach of the code and a 5/5 score would require evidence of innovative/unique practice that pushes the boundaries of company/industry practice. Other points taken into consideration include the manner in which any complaints have been handled by the site. The Black and Veatch Ltd. (B\&V) Glenfarg Water Treatment Works (GWTW) site was selected from more than 7000 eligible sites to receive one of the 64 gold awards and the accolade of the 'most considerate site' of 2009. Table 1 shows that on the monitor's first visit in May 2008 the site scored a 38/40 score and on a return visit in November 2008 scored a 40/40. In addition to the GWTW site, the awards panel found consistency of such high standards across other $\mathrm{B} \& \mathrm{~V}$ sites and an additional four silver and three bronze awards were secured at the 2009 ceremonies.

\section{Project Participants}

\subsection{The client: Scottish Water}

Scottish Water is a publicly owned company supplying approximately 2.3 billion litres of drinking water per day and treating nearly one billion litres of wastewater daily. Between 2006 and 2010 the company undertook a £2.4 billion improvement programme of works to improve drinking water and the disposal of wastewater from homes and businesses across Scotland. As a construction industry client Scottish Water demands excellence throughout its supply chain and has a legacy of success in relation to CCS registered sites. In 2007, Scottish Water's Blair Atholl project won the most considerate site award, to be followed in 2009 with the GWTW project. Other CCS gold awards include Glasgow's Katrine Water Project (2007) and Glencorse Water Treatment Works (2010). The three latter projects were all undertaken by the contractor noted below.

\subsection{The design and build partner}

$\mathrm{B} \& \mathrm{~V}$, a US-based company founded in 1915 , specialises in infrastructure development in energy, water, telecommunications, government, management consulting and environmental markets. The company mission is to 'build a world of difference'. The company has seven fundamental values (integrity, shared ownership, common purpose, stewardship, 
respect, accountability and entrepreneurship), and a code of conduct that focuses corporate success on individual performance including honesty, trustworthiness, diligence, inclusion and tolerance. In 2006 the company acquired the water business of M.J. Gleeson, doubling the size of B\&V's UK business.

\section{The project: Glenfarg Water Treatment Works}

The village of Glen Farg (Glenfarg) is situated in rural Perthshire close to the M90 motorway that connects Edinburgh and Perth. The existing Scottish Water treatment plant, located 2 miles west of the village adjacent to farmland serves a population of 180000 within the neighbouring Fife region. In $2007 \mathrm{~B} \& \mathrm{~V}$ was commissioned to undertake the $£ 4.3$ million upgrade to GWTW. The investment resulted in improved water quality and, in particular, addressing the risk from Cryptosporidium. The project comprised improvements to wash water, sludge recovery and disinfection as well as capital maintenance. Table 1 shows an outline overview of the project programme.

\section{Establishing a culture of collegiality on site}

The GWTW project employed a small number of direct and subcontracted workers on site at any one time. This allowed the site leadership to promote a strong culture of collegiality within the team, and the site signatory charter document (see section 6.5) assisted in reinforcing the aims of the CCS to the workforce. In addition, this initiative helped to promote camaraderie among team members. This created a virtuous cycle of positive behaviour that was sustained through an overall increase in individual and team motivation. However, it was the site leadership that fostered a culture of engagement and collaboration on site. This engendered a spirit of pride and passion throughout the team that reflects recent research emphasising the benefits derived from developing 'project chemistry' (Nicolini, 2002) and 'project affinity'(Dainty et al.,

\section{Oct 2007}

Oct 2007-Feb 2008

Feb 2008

Feb-May 2008

May 2008

May 2008

June 2008

July 2008

Aug 2008

Sept 2008

Sept 2008

$3 / 10 / 2008$

$31 / 10 / 2008$

$5 / 11 / 2008$

$6 / 11 / 2008$

$10 / 11 / 2008$

Nov 2008

Dec 2008

Feb 2008

\section{Contract awarded to $\mathrm{B} \& \mathrm{~V}$}

Procurement and forward planning and initial community liaison

Site set up with excellent facilities (showers, etc.) and traffic management (one-way systems, etc.) Main civils construction - sludge thickener and pipework

First CCS audit - 38/40 score

Main concrete benching $\left(200 \mathrm{~m}^{3}\right)$ of washwater tank brought forward by B\&V deliberately to avoid overlap with school summer holidays

$B \& V$ site operatives and staff decide to go much further with CCS initiatives and develop and sign a 'Glenfarg CCS charter'. First CCS action list developed and agreed between staff, operatives and Scottish Water Solutions project manager

Fife YEC is offered support by the site

Site worker suggests that the site should invite industry mascot Ivor Goodsite to visit Argnask School GWTW nominated for B\&V health and safety award as a result of excellent management of intrusive works on live water treatment works

Site manager attended CCS 'performing beyond requirements' regional workshop in Edinburgh YEC visit to B\&V and Scottish Water at Glenfarg Industry mascot Ivor Goodsite visit to Glenfarg Primary School Second CCS audit - 40/40 score. Audit was brought forward as next audit was to be January 2008 but B\&V had out-performed programme and intended to be off site by then

Site manager applies to become construction ambassador and science and engineering ambassador as a result of suggestion by CCS monitor

Site manager invited to YEC to meet chairman of Scottish Water Solutions

Meeting held with Elliot's (site cabin manufacturers) to discuss improvements to welfare facilities. Better mobile phone and smoking shelters provided

Planned continuous CCS improvement!

Anticipated project acceptance date -3 months ahead of programme, f0.75 M under budget, with no serious accidents and no water quality incidents

B\&V, Black and Veatch Ltd.; CCS, considerate constructors scheme; GWTW, Glenfarg Water Treatment Works; YEC, Young Engineers Club.

Table 1. Glenfarg Water Treatment Works timeline 
Engineering Sustainability

Volume 000 Issue ESO00
Considerate constructors

scheme: Glenfarg Water

Treatment Works

Murray, Forbes and Mason
2005) within construction project teams. A further essential ingredient of this collegial atmosphere was the full support from senior management within the contracting and client organisations. This support allowed the site leadership to act on suggestions made following the monitor's first visit and engage the team in brainstorming aligned to the eight-point code of considerate practice.

\section{Development of Innovative and Unique Practice}

The key to developing innovative and unique practice on site is enhanced through focused leadership in which creativity is encouraged and valued. While explicit and tacit knowledge is the mainstay of technical-related decision-making on construction projects, its contribution to 'softer' social responsibility issues is often less transparent. However, anecdotal evidence from CCS monitors suggests that too many site managers adopt a 'passive' and 'reactive' stance in relation to questions from the monitor's checklist. However, the site manager on the GWTW project adopted a 'proactive' approach and presented the CCS monitor with what appeared to be a fait accompli of best practice. His advice to colleagues was to 'note down everything you do - things that you consider as normal (using waste materials on other sites/protecting water courses, etc.) may get you extra CCS points - not everyone is as good as us - sell yourself. Present your list to the CCS site monitor'.

Anecdotal evidence suggests that even when contractors have demonstrated innovative practice, they are often too secretive about it. This could be considered a form of 'cultural' noise and is not compatible with championing continuous improvement or improving the image of the construction industry. As noted by Chrisp (1998) in his paper 'The theatre of civil engineering', construction sites must be the shop front for our industry and civil engineers are warned not to cloak their work in secrecy. Indeed, building firms have long been aware that construction sites function as business cards' (Glaser, 2008). Moreover, construction projects give a distinct 'outgoing message' to the local community, and every construction worker is in effect an 'ambassador' (Barthorpe, 2003). To this end, the GWTW project team has shared what it has learned in a Scottish construction centre demonstration project case study (Scottish Construction Centre, 2010). However, recent research (Smyth, 2010) warns that the overall effectiveness of case study documents to facilitate knowledge transfer is questionable, particularly when related to the transfer of tacit knowledge. This would suggest a need for dissemination by means of less formal methods such as seminars, and the GWTW project was the subject of an open invitation peer review process meeting as part of its SCC submission.

The following sections detail the innovative/unique practice uncovered by the CCS monitor. On the second visit to the site, each section scored a maximum mark, resulting in an overall $40 / 40$ score.

\subsection{Considerate}

This part of the code requires contractors to undertake work with positive consideration to the needs of local traders and businesses, site personnel and visitors, and the general public. The site team was particularly concerned about delivery vehicles passing through the village en-route to the site. Signage was erected at laybys at both ends of the village instructing drivers to contact the site for an escort through the village, and no deliveries were permitted along routes close to the primary school. The traffic plan was displayed in the village hall to ensure the public were aware of prescribed routes, and the construction programme was changed so as to undertake concrete works during school holidays. In addition, the contractor undertook to place new warning signage (see Figure 1) along existing roads leading to the site, and residential neighbours were complimentary about the temporary speed restrictions put in place. In addition, footpaths and fencing erected to separate the site from surrounding farmland was left for the farmer at the end of the project, and the contractor undertook frequent strimming of vegetation next to public footpaths. Operatives were also reminded of the need to maintain safe public access for hill walkers (Figure 2).

\subsection{Environmental}

Although each of the eight sections of the code carry equal weighting, the demonstration of good environmental practice, such as reducing waste and mitigating potential pollution (air, water, noise, light) has a significant bearing on improving the image of the industry. B\&V's accredited environmental management system (ISO 14001) was used as a backcloth to reinforce environmental site practice. The key issue was the

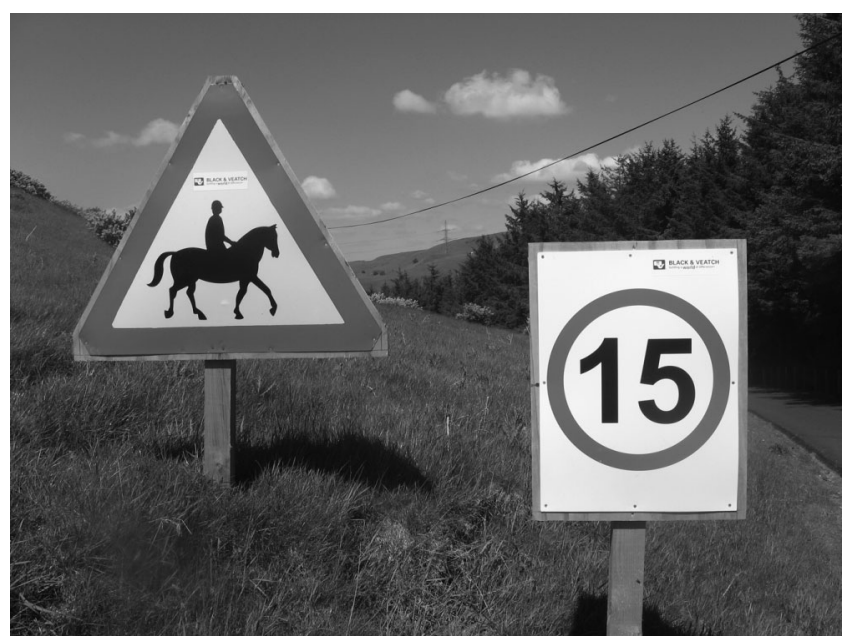

Figure 1. New warning signage 
Engineering Sustainability

Volume 000 Issue ESO00
Considerate constructors

scheme: Glenfarg Water

Treatment Works

Murray, Forbes and Mason

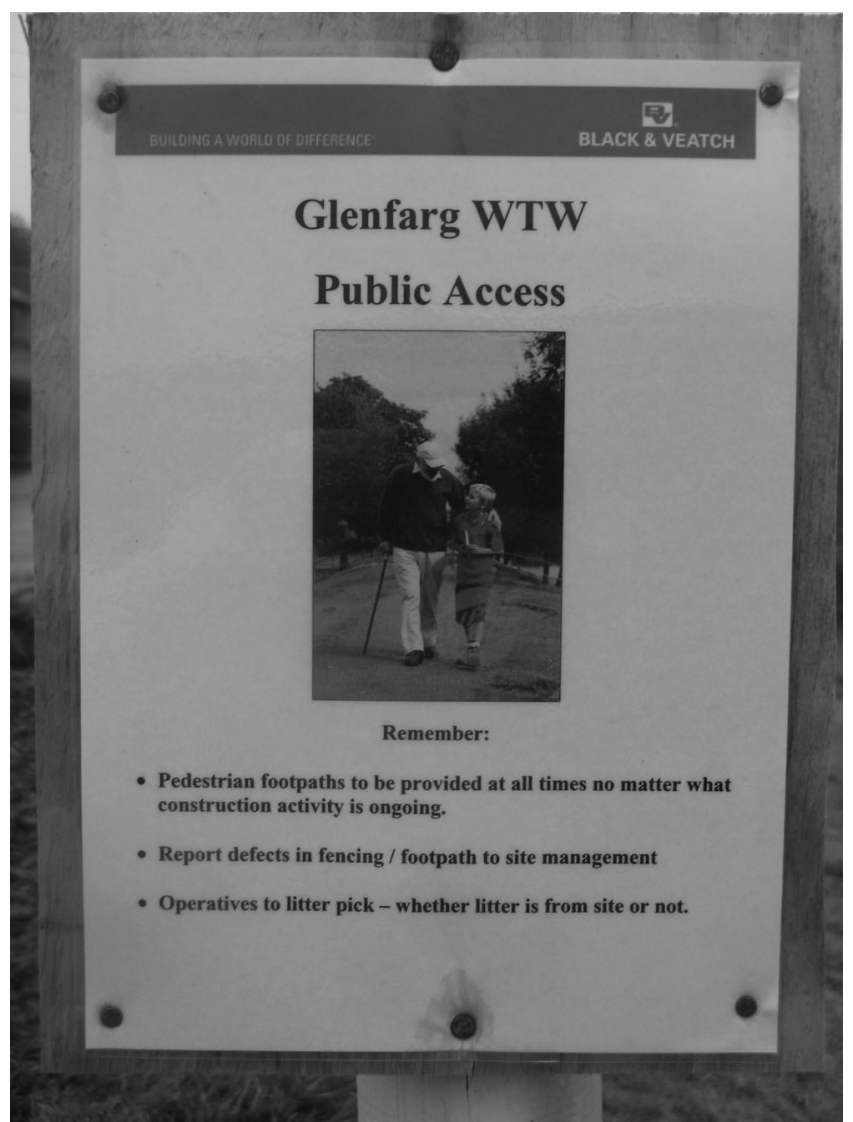

Figure 2. Public access information poster

maintenance of the current water supply to Scottish Water's customers without interference from the construction works. This objective helped to frame the overall approach to environmental practice on site. In particular, the sludge thickeners were constructed from pre-cast concrete rather than in situ to minimise material wastage and noise. The site also employed measures to save water and reduce energy consumption, and external works included protection to trees. Innovative signage was also employed to remind workers of the close proximity of farm livestock. Indicative of the drive for continuous improvement was a meeting with the site cabin supplier to discuss options for using more environmentally friendly cabins on future projects.

\subsection{Cleanliness}

It is rare to see this section securing a top $5 / 5$ score from monitors. However, on this site the need to maintain excellent standards of hygiene were explicit and were clearly understood by everyone on site. This meant that routine activities such as general housekeeping around the site and within the existing plant were undertaken with exceptional care. This level of considerate practice was partly driven by the client's requirements, but was also a self-sustaining cause and effect of workforce engagement that links this section of the code with two others. The link between cleanliness, safety and the environment, while not explicitly linked in the code, are nonetheless related in relation to reducing slips, trips and other occupational health issues; and recycling and waste reduction practice on site. This project was able to demonstrate the synergy - workforce pride and passion - that can be gained from considering their linkage.

\subsection{Good neighbours}

Establishing contact with neighbours who are affected by the work and maintaining communication from pre-start to completion is one of the key requirements of the CCS. The site team developed a high profile within the community through attendance at community council meetings before the start on site in January 2008. Once on site a communications strategy was established and this was to see monthly programmes (highlighting times of large deliveries) displayed on notice boards at the main road/site entrance and within the village shop (see Figures 3 and 4) A neighbours' satisfaction survey was also piloted, and although this did not generate a high response, it did demonstrate the need to be proactive and not to assume that no formal complaints equates to happy neighbours. Of particular significance, neighbours appreciated friendly operatives and staff waving and saying 'hello'. The site also contributed to Glenfarg fete; raising money for Glenfarg village hall.

The neighbourhood practice witnessed on the project falls largely within the project stakeholder management arena. While this paper does not examine this topic in detail, the approach

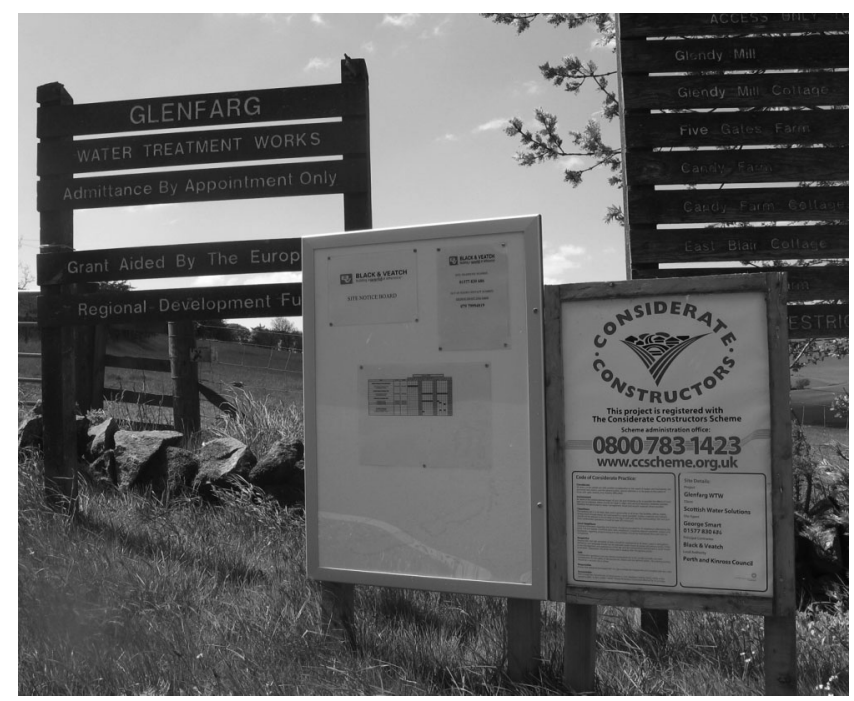

Figure 3. Signage at main road junction leading to site 
Engineering Sustainability Volume 000 Issue ES000
Considerate constructors

scheme: Glenfarg Water

Treatment Works

Murray, Forbes and Mason

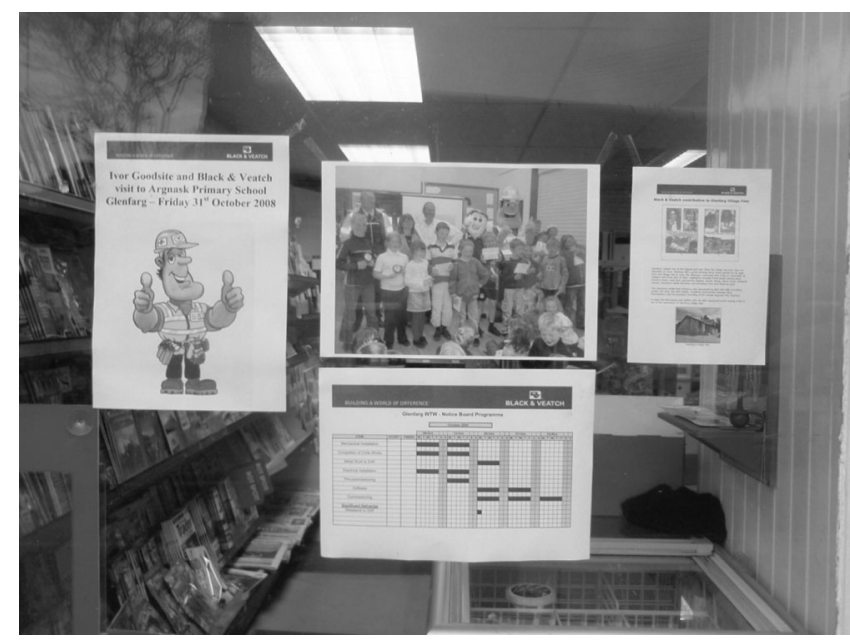

Figure 4. Village shop posters

taken to engage neighbours reflects guidance (Hadi et al., 2004) and good practice observed elsewhere (Olander and Landin, 2008), and reflects the need to recognise the potential power that opposition groups (Teo and Loosemore, 2010) can exert over project objectives. The project team acknowledged neighbourhood acceptance as a critical success factor and set up frameworks for stakeholder communication to be open, trustworthy, cooperative, respectful and informative.

\subsection{Respectful}

This section of the code requires contractors to have a behavioural code that ensures the site and its workers are presented in a respectable and professional manner. This partly reflects the aims documented by the Respect for People Working Group (2000), whose report noted the 'chasm' between the respect demonstrated towards 'blue-collar' workers and that shown to 'white-collar' workers.

Following on from the monitor's first visit, the operatives, staff and subcontractors agreed and signed up to a Glenfarg CCS charter. Figure 5 shows the photographs of the signatories that were displayed on a poster reinforcing a team commitment to improving practice across the eight-point code. A suggestion box and action list were integral to this goal. This reflects the importance of workforce engagement and the potential for developing project chemistry (Nicolini, 2002) and affinity (Dainty et al., 2005), as noted previously. A further issue related to a respect for people initiative concerned the welfare provision on site, with particular reference to the availability and use of showers. While this remains a contentious issue within the industry, the contractor presented operatives with

4 free branded kit bags containing new PPE, towels and shower gel to encourage the use of the showers on site.

\subsection{Safe}

Raising occupational health and safety standards among the workforce and protecting the general public and visitors is core to this section of the code. B\&V's behaviour on safe sites initiative instilled a positive safety culture during the works and an extensive poster campaign assisted communications. Key to this was the high level of engagement with the workforce, which included the use of a daily observational rating system. This involved the workforce using the method statements and risk analysis documents as guidance for daily activities rather than simply a 'tick box' paper exercise. This was particularly important given the need for emergency procedures while working in confined spaces within the existing plant. To motivate workers on site 360 degree feedback was encouraged and this allowed the site management to understand the mood of the workforce. Communication played a vital role and photographs of site practices were displayed to emphasise good practice and discourage negative behaviours. The contractor is also a regular winner of gold and silver awards from the Royal Society for the Prevention of Accidents (RoSPA, 2010) and this reflects a mature occupational health and safety management system and culture.

\subsection{Responsible}

This section seeks to ensure that everyone associated with the site understands, implements and complies with the eight-point code. One of the most enduring aspects concerns the positive promotion of the industry to schoolchildren, college students and other youth groups as a means to encourage them to consider a career in construction. For many years, opinion surveys (MORI, 1998) have uncovered too many children with high levels of ambivalence towards construction, often citing similar stereotypical views (dangerous and dirty) as adults. In 2003, the CCS sought to play its part in addressing this problem through the creation of a costumed character known as Ivor Goodsite (2010). As a construction industry mascot Ivor is very professional and is always dressed appropriately for working on a construction site.

The site team invited Ivor (the costume required a willing volunteer from the site!)to attend Argnask primary school within the village, where the friendly builder spoke to pupils about the dangers of playing near building sites and the wide range of careers in the construction industry. Ivor's contractor friends explained the broad concept of the works being undertaken, and engaged the pupils in a series of fun activities including decorating mugs with construction industry images, including Ivor. Prizes for the best posters were awarded and the painted mugs were presented to site workers as a means to facilitate a two-way affinity. This was particularly innovative, in that it emphasised to the workers the need for them to maintain similar professional credentials as Ivor. Figure 6 shows Ivor on site following his school visit. 
Engineering Sustainability

Volume 000 Issue ESO00
Considerate constructors

scheme: Glenfarg Water

Treatment Works

Murray, Forbes and Mason

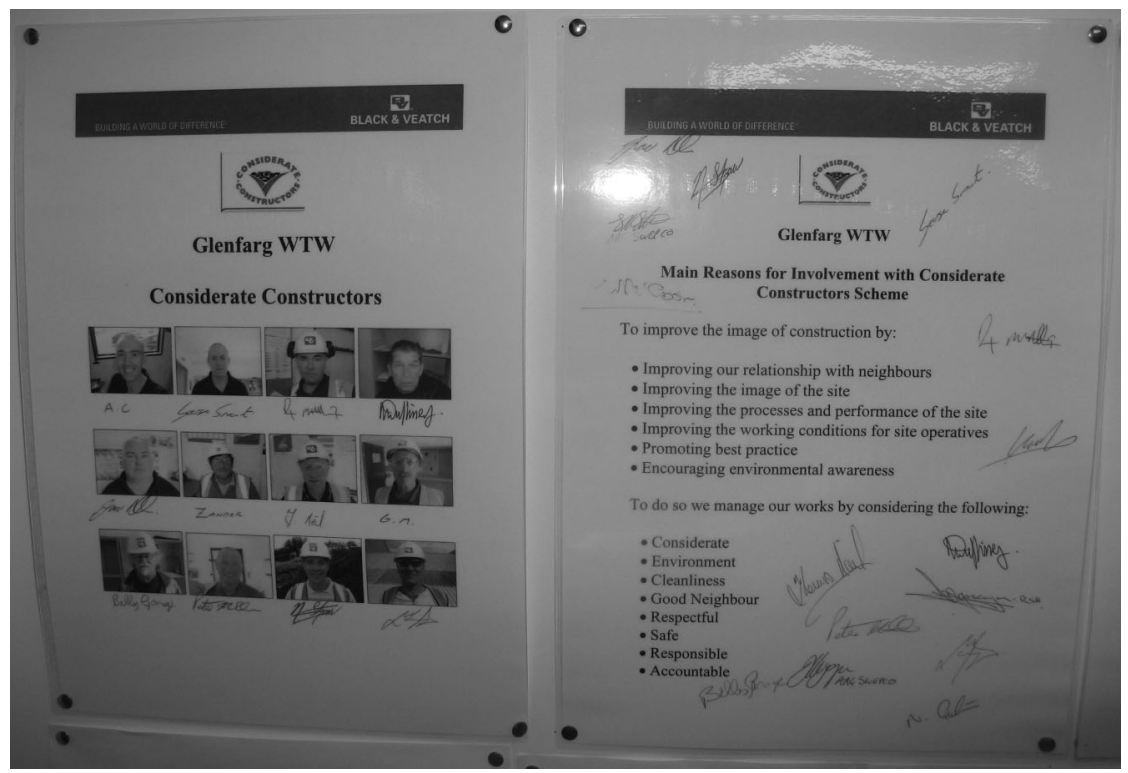

Figure 5. Considerate constructors scheme charter

In addition to the school visit, the site team extended an invitation to the Young Engineers and Science Club (2010) based at Adam Smith College in Kirkcaldy. Talks were given by the client and contractor on the water treatment processes, mechanical, process and electrical engineering, the use of process and instrumentation diagrams, site safety and CCS initiatives before the group were given a guided tour of the

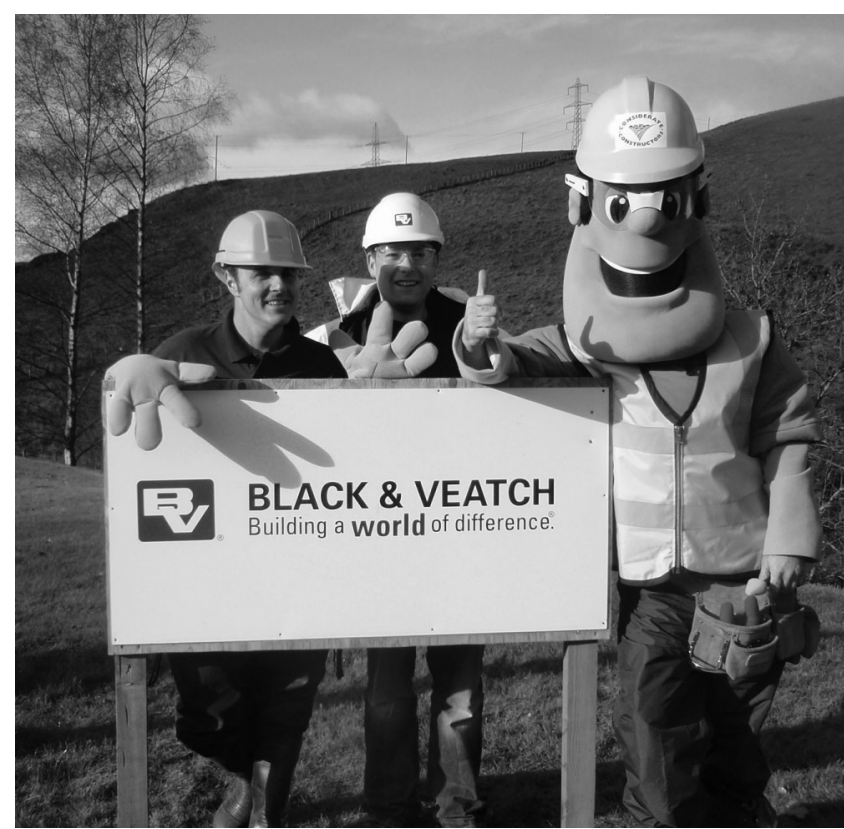

Figure 6. Ivor Goodsite visits site works. As a legacy of these visits, the contractor authorised the site manager to become a science and engineering ambassador (SEA, 2010) to assist in the promotion of civil engineering to young people.

\subsection{Accountable}

In this section the contractor must demonstrate they have complied with scheme's requirements to display CCS posters, and that company contact details are available to the public. Figure 4 shows the CCS site poster clearly visible for the public at the main road junction leading to the site. This section tends to reflect the core values of a company and how these impact on site practice. The contractors' values (respect, integrity, stewardship, and accountability) were integral to the support that the site manager received in developing CCS initiatives, and the workforce were fully aware of their important role through inductions and toolbox talks. After the monitor's first visit site staff and operatives had several meeting to agree further actions. This professionalism was bolstered by the contractor's accreditation (BS EN ISO 9001:2000 and 14001:2004) that provided a backcloth to work from. In addition, the site manager attended a CCS workshop (Edinburgh, September 2008) that assists site managers to perform beyond the basic requirements and provided examples of what sites have done to win national awards.

\section{Discussion}

The previous eight sections have documented the site practices that were considered by the CCS awards panel to be suitably innovative and often unique to merit the award of the 2009 CCS most considerate site. While these practices were akin to 
Engineering Sustainability

Volume 000 Issue ESO00
Considerate constructors

scheme: Glenfarg Water

Treatment Works

Murray, Forbes and Mason what researchers (Gray and Davies, 2007) define as existing process concepts, the overall level of synergy was noteworthy. Moreover, the site leadership emphasised the need to plan for success by aligning the eight-point CCS code to established project management principles and practice. Indeed, as previously noted, 'soft' management skills were a key constituent of the project management. The site leadership emphasised that innovative practice can be nurtured through encouraging 'buy-in' from the site team, and that developing a project-specific CCS action list can be fun! Moreover, they encouraged belief in the team by emphasising that they could make a difference through their behaviour. The engagement and subsequent motivation of the workforce has similarities to larger UK projects (Doherty, 2008), where symbolic site posters and newsletters have been employed as a means to improve communication and forge a collegial culture on sites. On the GWTW project, this lead to an alignment of client, contractor and workforce objectives that was the catalyst for successful completion of the project and indeed further recognition from the client.

A further key focus throughout all stages of the project was that of community liaison. The site leadership emphasised the need to establish a communication protocol with the community council and neighbours to discuss engagement including potential charity activities. Moreover, using a questionnaire to elicit the neighbours' opinions on the project provided an opportunity to take actions where required and provide feedback to them during regular meetings. Since January 2010 this has become part of the CCS recommendation for considerate practice. The lasting legacy of such practice can help to enhance the reputation of the companies involved in a project and, as noted by the site manager at Glenfarg, 'the most effective and innovative CCS initiatives (charter and neighbours survey etc.) cost little other than people's time, energy and commitment'.

\section{Conclusion}

Since 1997, the CCS has assisted the construction industry to improve its image. While this remains the overriding objective now it is evident that the industry has evolved. The development of site welfare conditions and workforce engagement has no doubt contributed to improvements. Environmental issues are now dominant within the industry and while each section of the eight-point code carries equal weighting, it is undeniable that reducing a site's carbon footprint has become a key concern for many contractors. However, as the GWTW project emphasises, it is essential to look over the perimeter hoarding and engage with a neighbourhood during the construction phase. The overriding lesson from this project is that the development of belief, passion, engagement and pride costs comparatively little when a desire to maintain the reputation of a company and the image of the industry is part of standard project management practice. This could be a noteworthy issue for the heightened awareness of soft management skills within the development of the industry project management body of knowledge.

\section{REFERENCES}

Barthorpe S (2003) The Considerate Constructors Scheme - A Way to Good Relations, Proceedings of 3rd Nordic Conference, Construction Economics and Organization, Lund, 23-24 April, pp. 11-20.

Barthorpe S (2010) Implementing corporate social responsibility in the UK construction industry. Property Management 28(1): 4-17.

Bennett J, Croome D and Atkin B (1989) Investing in Building 2001. Centre for Strategic Studies in Construction, University of Reading, UK.

Centre for Strategic Studies in Construction (1988) Building Britain 2001. University of Reading, Reading, UK.

Chrisp M (1998) The theatre of civil engineering. ICE Proceedings of Civil Engineering: Civil Engineering 126(2) 98-99.

City of London. Considerate contractor scheme. See http:// www.cityoflondon.gov.uk/Corporation/LGNL_Services/ Business/Business_support_and_advice/considerate_ contractor_scheme.htm\#ccs (accessed 02/04/10).

Considerate Constructors Scheme. History of the considerate constructors scheme, 2010. See http://www.ccscheme.org. uk/index.php/ccs-ltd-ccsltd/what-is-the-ccs2/history-css-ltd (accessed 02/04/10).

Dainty ARJ, Bryman A, Price ADF et al. (2005) Project affinity: the role of emotional attachment in construction projects. Construction Management and Economics 23(3): 241-244.

Doherty S (2008) Heathrow's Terminal 5: History in the Making. Wiley-Blackwell, Oxford.

Glass J and Simmonds M (2007) Considerate construction: case studies of current practice. Engineering, Construction and Architectural Management 14(2): 131-149.

Glaser MA (ed.) (2008) The construction site: history and present of fascination. In Construction Site. Lars Muller Publishers, Switzerland.

Gleeson D (2005) MJ Gleeson Group plc. Corporate social responsibility report, foreword. pp. 3. See http://www. corporateregister.com/a10723/mjg05-csr-uk.pdf (accessed 28/04/10).

Gray C and Davies RJ (2007) Perspectives on experiences of innovation: the development of an assessment methodology appropriate to construction project organizations. Construction Management and Economics 25(12) 1251-1268.

Hadi M, Rao S, Sargant H and Rathouse K (2004) Working with the community: a good practice guide for the construction industry. Building Research Establishment, Watford. 
Engineering Sustainability

Volume 000 Issue ESO00
Considerate constructors

scheme: Glenfarg Water

Treatment Works

Murray, Forbes and Mason
Ivor Goodsite (2010) See http://www.ivorgoodsite.org.uk (accessed 20/04/10).

Jones P and Comfort D (2006) Corporate social responsibility and the UK construction industry. Journal of Corporate Real Estate 8(3): 134-150.

Latham M (1994) Constructing the Team: Final Report; Joint Review of Procurement and Contractual Arrangements in the United Kingdom Construction Industry. HMSO, London.

Loosemore M and Phua F (2011) Responsible Corporate Strategy in Construction and Engineering: Doing the right thing? Spon Press, London.

5 MORI (1998) Children's attitudes towards the construction industry - a research study among 11-16 year olds. Research Report undertaken for the CITB (no longer available).

Murray M and Dainty A (2009) Corporate Social Responsibility in the Construction Industry. Taylor \& Francis, London.

National Contractors Group and Centre for Strategic Studies in Construction (1991) Building Towards 2001. University of Reading, Reading, UK.

6 Nicolini D (2002) In search of 'project chemistry'. Construction Management and Economics 20: 167-177.

7 Olander S and Landin A (2008) A comparative study of factors affecting the external stakeholder management process. Construction Management and Economics 26: 553-561.

Respect for People Working Group (2000) A Commitment to people 'our biggest asset'. A report from the Movement for
Innovation's working group on Respect for People. See www.constructingexcellence.org.uk/pdf/rfp/rfp_report.pdf (accessed 20/07/10).

RoSPA (Royal Society for Prevention of Accidents) (2010) Gold awards. See http://www.rospa.com/Awards/Winners/2009/ gold-award.aspx (accessed 29/04/10).

Science and Engineering Ambassadors (2010) Becoming a SEA. 8 See http://www.setpointscotlandseas.org.uk/becoming.htm (accessed 29/04/10).

Scottish Construction Centre (2010) Demonstrations project, considerate constructors site, Glenfarg. See http://www. scocon.org/filelibrary/demonstration_projects/ Glenfarg_case_study_FINAL_AD.pdf (accessed 14/09/10).

Smyth H (2010) Construction industry performance improvement programmes: the UK case of demonstration projects in the 'Continuous Improvement' programme. Construction Management and Economics 28(3): 255-270.

Teo MMM and Loosemore M (2010) Community-based protest against construction projects. The social determinants of protest movement continuity. International Journal of Managing Projects in Business 3(2): 216-235.

The Construction Industry Board (1996) Constructing a Better Image: A report by Working Group 7 of the Construction Industry Board. Thomas Telford, London.

Young Engineers and Science Clubs (2010) News, Adam Smith College, Kirkcaldy. See http://www.yecscotland.co.uk/ clubnews.html (accessed 29/04/10).

\section{WHAT DO YOU THINK?}

To discuss this paper, please email up to 500 words to the editor at journals@ice.org.uk. Your contribution will be forwarded to the author(s) for a reply and, if considered appropriate by the editorial panel, will be published as discussion in a future issue of the journal.

Proceedings journals rely entirely on contributions sent in by civil engineering professionals, academics and students. Papers should be 2000-5000 words long (briefing papers should be 1000-2000 words long), with adequate illustrations and references. You can submit your paper online via www.icevirtuallibrary.com/content/journals, where you will also find detailed author guidelines. 